\title{
SEGURANÇA PÚBLICA E LÓGICA NEOLIBERAL: A REALIDADE BRASILEIRA
}

\author{
Kíssila Teixeira Mendes*
}

\begin{abstract}
Resumo: A pesquisa se baseia na revisão bibliográfica sobre segurança pública e Neoliberalismo e no uso de dados quantitativos, posteriores aos anos 2000, que permitam analisar, em um primeiro momento, a lógica neoliberal e sua inserção no Brasil e, posteriormente, a presença desta orientação nas políticas criminais e penais. $\mathrm{O}$ trabalho tem o objetivo de compreender, a partir de uma análise pautada na criminologia crítica, os mecanismos estatais que definem o objeto e que reagem ao crime, e parte da hipótese de que a responsabilização pelos níveis alarmantes de criminalidade na sociedade é direcionada para a população pobre (criminalização da pobreza).
\end{abstract}

Palavras-chave: Segurança pública; Neoliberalismo; Violência. Brasil.

\section{Public safety and the neoliberal logic: the Brazilian reality}

Abstract: The research is based on the literature review related to public safety and Neoliberalism and the use of quantitative data subsequent to the 2000s to report on, at first, the neoliberal logic and its insertion in Brazil and, subsequently, the presence of this orientation in the criminal policies The research has the objective to understand, from a guided analysis based on critical criminology, the state mechanisms that define the object and reacting to crime, and on the assumption that the coverage of alarming levels of crime in society is directed to the poor population (criminalization of poverty).

Keywords: Public safety; Neoliberalism; Violence. Brazil.

\section{Seguridad pública y la lógica neoliberal: la realidad brasileña}

Resumen: La investigación se basa en la revisión bibliográfica sobre seguridad pública y neoliberalismo y el uso de datos cuantitativos, posteriores a los años 2000,

* Universidade Federal de Juiz de Fora - UFJF, Juiz de Fora-MG, Brasil (kissilamm@hotmail.com). Recebido em: 22/11/2014 - Aceito em: 11/05/2015. 
que permitan analizar, en un primer momento, la lógica neoliberal y su inserción en Brasil y, posteriormente, la presencia de esta orientación en las políticas criminales y penales. El objetivo del trabajo es comprender, desde un análisis basado en la criminología crítica, los mecanismos estatales que definen el objeto y que reaccionan al crimen, y parte de la hipótesis de que la responsabilidad por los alarmantes niveles de criminalidad en la sociedad se dirige a la población pobre (criminalización de la pobreza).

Palabras clave: seguridad pública; Neoliberalismo; Violencia; Brasil.

\section{Introdução}

O presente artigo tem como objetivo analisar, com ênfase para o contexto brasileiro, a influência da orientação neoliberal nas políticas criminais e penais que se caracterizam, sobretudo, através de uma política punitiva. Será apresentada uma análise do neoliberalismo inserido no contexto brasileiro e, posteriormente, nas políticas de segurança pública. Serão incluídos também dados estatísticos, que compreendam um período posterior aos anos 2000, sobre a realidade carcerária e índices de segurança no Brasil.

No decorrer do artigo é possível perceber que a política punitiva é apresentada como forma primordial de estabelecer a ordem, e serão trabalhados os desfechos dela. É importante ressaltar que a escolha pelo estudo dos aspectos punitivos se deu pelos impactos destes na vida cotidiana, com a busca constante dos aparelhos estatais por uma limpeza urbana das classes ditas perigosas, e na influência de tais ações sobre os imaginários e representações sociais. É evidente, entretanto, que tal realidade não se explica somente pelos impactos de políticas neoliberais, pois, como veremos, não é possível definir que houve no Brasil um governo neoliberal. O objetivo do artigo é fazer um recorte que possibilite compreender parte do processo macrossocial e mostrar como as políticas criminais e de segurança pública possuem intrínseca relação com as ideologias políticas e formas de governo. 


\section{1 - Lógica Neoliberal e sua inserção no contexto brasileiro: breve histórico}

A fim de melhor contextualizar a temática será apresentado um breve histórico, tanto a nível mundial quanto no âmbito nacional, partindo do surgimento do Liberalismo enquanto ideologia mundial até os dias atuais, com a análise do neoliberalismo inserido no contexto brasileiro e, posteriormente, nas políticas de segurança pública. Reconstituir tal histórico em poucas páginas certamente dará margem a simplificações. Portanto, deve ficar claro que a pretensão é realizar uma reconstituição acessível que visa dar suporte ao tema trabalhado. Macedo (1995) alerta para a dificuldade de se conceituar o Liberalismo por este ser, além de uma doutrina política, um pensamento sócio histórico: surge no século XIX no contexto do Renascimento e da Reforma, de cunho humanista, e traz o individualismo e a liberdade como valores principais, possuindo ainda como traços comuns o racionalismo, individualismo, universalismo, reformismo e progressismo. No final do século $X X$ se transforma em ideologia global, partindo do princípio básico de que o Estado se limita a si mesmo com o objetivo de fazer emergir forças aleatórias e, inclusive, contrárias a ele. Assim, o liberalista se utiliza da razão e da moral para avaliar quais tradições e costumes são favoráveis ao progresso e, portanto, devem ou não ser preservados, diferentemente de posições conservadoras ou revolucionárias radicais. Entre suas características principais estão: distinção entre público e privado; liberdade religiosa; defesa dos homens como cidadãos; e ser contrário aos excessos do governo. Já uma visão econômica entende por liberalismo "uma determinada concepção de Estado, do qual o Estado tem poderes e funções limitadas, e como qual, se contrapõe tanto ao Estado absoluto, quanto ao Estado que hoje chamamos de social." (BOBBIO, 1994: 7).

No Brasil, segundo Costa (1999), as ideias liberais foram responsáveis por fundamentarem diversas revoltas emancipatórias. Porém, sobretudo após a independência em 1822, quando passa a ter maior influência, a elite interessada em manter suas 
propriedades e as economias de importação e de exportação, sem a discussão de combate aos conflitos e as desigualdades sociais, faz o ideal liberalista partir para um viés conservador desde sua origem no país.

Com a crise de 1929, caracterizada principalmente pela superprodução capitalista, surgiu nas classes dominantes um receio de expansão do socialismo, o que levou a um recuo do liberalismo e possibilitou a ascensão de regimes totalitários pelo mundo. Foi após a Segunda Guerra Mundial, porém, que houve a maior crise do capitalismo exploratório "liberal", e foi quando segundo Cancian (2007), surgiu o Estado de Bem Estar Social na busca de um intermédio para os conflitos sociais propondo a prestação de serviços sociais por parte do Estado que assegurassem os direitos e a diminuição das desigualdades. Entretanto, tal organização política e econômica se apresentou de diferentes maneiras nos países nos quais foi implementada. No Brasil não houve uma estruturação do Estado de Bem Estar Social semelhante aos países centrais, mas observa-se uma forte intervenção do Estado a partir da Era Vargas (1930-1945) até o fim da ditadura militar (1964-1985), embora os maiores beneficiados com os gastos do setor público tenham sido, historicamente, os empresários e os estrangeiros.

Foi em meados de 1970, de acordo com Mauriel (2006), que surgiram na Europa as maiores críticas ao (e a posterior crise do) Estado de Bem Estar Social (bem como a derrocada do Socialismo), que alegavam que os gastos do governo em políticas públicas, somado aos efeitos das políticas assistencialistas no comportamento dos indivíduos, trariam como conseqüência a paralisação da economia. Além disso, o Estado de Bem Estar Social, de acordo com Negrão (1996), favoreceu um crescimento de politização da sociedade nas questões econômicas e sociais, o que gerou maior número de exigências e expectativas que, consequentemente, foram quebradas pela incapacidade do governo de se adequar e universalizar tais demandas, o que gerou uma crise de governabilidade das democracias (ou o limite do Estado Social). A saída para tal crise, de acordo com visões teórico políticas 
conservadoras $^{1}$ seria impor limites à democracia, diminuindo o papel de Estado como mediador dos anseios populares, limitando sua função à economia.

Sendo assim, segundo Mauriel (2006) surge uma nova concepção de Estado que aponta para subordinação à globalização financeira, privatizações, centralização no Executivo e para fortes críticas a elementos de proteção social e de direitos de participação que interfiram no interesse da economia: o Neoliberalismo. Este novo ideal político-econômico busca limitar o poder do Estado e também o de participação política da sociedade civil. Assim, de acordo com Sader (2013), o neoliberalismo é o marco da passagem de um mundo bilateral para um unilateral, de um modelo de Bem Estar Social para um liberal de mercado e "representa o projeto de realização máxima do capitalismo, na medida em que visa a mercantilização de todos os espaços das formações sociais." (SADER, 2013: 135).

O neoliberalismo se aproxima do liberalismo clássico, segundo Mancebo (2002), ao ter como principio básico o mercado, que extrapola o nível econômico e perpassa a organização do Estado e da sociedade, limitando a intervenção estatal e racionalizando o governo. Entretanto, enquanto no liberalismo clássico o mercado é tido como realidade quase natural, o mercado neoliberal só existe a partir de formas artificialmente arranjadas a partir de condições jurídicas, políticas e institucionais. A lógica de mercado, porém, faz parte do ideário neoliberal também ao estruturar as relações pessoais e sociais, implicando em um novo arranjo de subjetividade individualista e utilitarista. Mas, se o postulado liberal da liberdade é exacerbado no neoliberalismo, há um rebaixamento do princípio da igualdade, pois "a desigualdade permite o equilíbrio, a complementação de funções, fomenta a competição e desse modo, promove o desenvolvimento" (MANCEBO, 2002: 14).

\footnotetext{
${ }^{1}$ Cujos principais entusiastas são Michel Crozier, Samuel Huntington e Joji Watanuki, autores da obra "A crise das democracias", de 1975, considerada, a nível teórico e político, como a ressurreição do neoliberalismo.
} 
|208|

Segurança pública e lógica neoliberal: a realidade brasileira

No Brasil, segundo Sader (2013), foi possível ao governo militar, em um primeiro momento, fortalecer economicamente o Estado e expandir a economia, embora mediante o ingresso do capital estrangeiro nas grandes obras por ele promovidas. Segundo Miranda, Miranda e Veríssimo (2008), após o período desenvolvimentista vivenciado nas décadas de 1960 e 1970, observase, mais exatamente a partir de 1990, um ajustamento aos modelos descritos no Consenso de Washington ${ }^{2}$, com o aprisionamento do Estado voltado para um equilíbrio econômico, o que levou o país a reduzidos investimentos na área de políticas públicas. A Carta Magna de 1988, tida também como "Constituição Cidadã", os movimentos e as entidades sociais que surgem em meados de 1980, de fato, caracterizaram conquistas sociais e de direitos e igualdade. Porém, como alega Sader (2013), já no governo Sarney, a Constituição encontrou adversários, sob o argumento de que tais garantias atribuídas aos cidadãos, impediriam o avanço econômico e transformariam o Estado em "ingovernável".

Com o fracasso do governo Sarney e posterior eleição de Collor, a transição democrática não foi capaz de democratizar o poder econômico, os meios de comunicação e a propriedade de terra, consolidando a posição do Brasil como um dos países mais desiguais do mundo. Com Collor o Brasil foi apresentado às diretrizes neoliberais, mas seu impeachment refletiu-se em atraso no projeto neoliberal no Brasil. Foi com Fernando Henrique Cardoso (tanto como ministro da Fazenda no governo de Itamar Franco quanto em seus dois mandatos presidenciais) que tivemos dois fenômenos primordiais: "financeirização da economia" e "precarização das relações de trabalho" (SADER, 2013: 138). Nessa perspectiva, "o Estado se tornou refém do capital" (SADER, 2013:

\footnotetext{
${ }^{2} \mathrm{O}$ Consenso de Washington, modelo criado pelo Banco Mundial e pelo FMI, foi um encontro, segundo Negrão (1996), a principio acadêmico, onde estavam presentes entidades privadas, economistas liberais latino americanos, entre outros, e que, posteriormente, passou a ser aplicado como troca por concessão de crédito do FMI, prevendo a estabilização da economia nos países periféricos a partir de reformas estruturais liberalizantes.
} 
138), ao mesmo tempo em que as relações de trabalho foram informalizadas, o que contribuiu para a exclusão social dos trabalhadores.

Segundo Soares (1999), se nos países centrais a discussão centrava-se em não permitir mecanismos de gerenciamento do Estado na economia, nos países periféricos, como o Brasil, os esforços se concentraram em inviabilizar políticas de cunho social. Dessa forma, na América Latina, o ajuste neoliberal se consolidou através do Consenso de Washington. Segundo Fiori (2013) na década de 1990, a maior parte dos governos sul americanos alinharam-se ao projeto liberal, o que, posteriormente foi responsável pelas grandes crises cambiais, sociais e políticas sofridas por esses países. Tal fato, de acordo com este autor, foi decisivo para a chamada "virada à esquerda" nos governos, modificando os projetos políticos do continente, que se uniram em grandes blocos ideológicos e de poder. Porém, “o declínio do projeto conservador não havia cedido lugar a um novo 'modelo de desenvolvimento', no sentido abrangente que essa expressão teve no passado." (GARCIA, 2013: 56). Tal afirmação, como veremos, se confirma sobretudo na área de segurança pública.

Segundo Sader (2013), o governo de Luiz Inácio Lula da Silva (e posteriormente o de Dilma) pode ser definido como pósneoliberal por três características principais: implementação de políticas públicas nacionais, integração regional com países do Sul, e papel interventor do Estado. Porém, embora haja a mudança das prioridades de resistência à recessão, estas não foram capazes de romper com "os retrocessos impostos pelo neoliberalismo: a desindustrialização, o protagonismo de exportador primário, uma sociedade fragmentada, as ideologias consumistas." (SADER, 2013: 141).

A perspectiva neoliberal, segundo Mauriel (2006), desvaloriza questões estruturaise, em contrapartida, as coloca como individuais e de desvantagem de capacidades de cada membro da sociedade em particular. Assim, as políticas públicas, se baseadas neste paradigma, servem como meio de possibilitar capacidades 
através da "liberdade" desses indivíduos conquistarem bens materiais, e não como mudanças na estrutura de renda e direitos.

\section{2 - Neoliberalismo e segurança pública: relações e controvérsias nas políticas criminais e penais}

Um dos campos em que o modelo político e econômico neoliberal se mostra central é no âmbito das políticas criminais, sendo o objetivo deste tópico problematizar tal relação. De acordo com Dornelles (2003), a partir de um discurso de promoção de bem estar coletivo, tais políticas acabam por legitimar ações repressoras e de controle social do próprio Estado. Parte-se então para um modelo de "lei e ordem", muito forte nos Estados Unidos, onde é criado um estereótipo de inimigo comum da sociedade, responsabilizado por todos os problemas estruturais da nação.

Porém, como ressalta Santos (2007), é importante não se aprisionar em visões que culpabilizam unicamente o sistema capitalista pela existência do quadro de violência, pois, logicamente, tal quadro se encontra em outros sistemas políticos e econômicos. Logo, se trata aqui de compreender como a conjuntura política e econômica interfere na realidade das relações sociais e ordenamento jurídico e como se encarna em certos princípios e valores das políticas de segurança. Assim, podemos partir de uma análise pautada na criminologia crítica, cujo objeto é o crime em si e o objetivo não é saber o porquê de alguém se tornar um criminoso, e sim os mecanismos estatais que definem o objeto e que reagem ao crime.

Em entrevista concedida à revista Caros Amigos em agosto de 2003 (SOUZA et al., 2003), Nilo Batista diz ser "chocante" o fato dos discursos políticos, independente de posições partidárias e ideológicas, serem exatamente os mesmos quando se trata da questão criminal. Dessa forma, o medo é utilizado como recurso estratégico, o que leva à criminalização também das relações sociais, em consonância com uma pauta econômica que favorece uma política genocida em diversas partes do mundo. 
Zaffaroni, em entrevista a Tavares (2013), reforça a posição de que as políticas criminais e penais da América Latina são decisões políticas fortemente influenciadas por modelos europeus e norte americanos de crescimento da repressão.

Karam (1996) atenta que também o interesse de amplos setores da esquerda (denominada Esquerda Punitiva) pela segurança pública se voltou para um pragmatismo eleitoral no sentido de ampliação do discurso de repressão e punição, e a aproxima da lógica neoliberal, construindo a imagem de que um bom sistema penal é aquele que pune severamente, seja a quem for. O clamor contra a impunidade e contra a corrupção acaba por legitimar ações cada vez mais reacionárias, rompendo tanto com conquistas da própria esquerda, quanto com princípios do Estado de Direito. Tal pedido também é em vão, pois o verdadeiro papel da repressão não é o de justiça social, e sim a manutenção das estruturas de poder. Esses conceitos neoliberais aderidos pela maioria da população e dos governantes os impedem de buscar uma compreensão mais profunda da realidade e de verem que a violência é um subproduto necessário ao capitalismo.

Wacquant (2008), ao escrever sobre o estado penal norte americano, salienta o aumento de cinco vezes no potencial punitivo, comparando estatísticas de 1975 e 1999. Tal fato, segundo o autor, ocorre não por conta de uma reestruturação aos moldes capitalistas, nem tampouco por uma "guerra contra o crime", mas sim por outros traços característicos, como explicitado a seguir:

$\mathrm{O}$ alvo na verdade eram determinadas categorias de ilegalidades cometidas em um setor bem definido dos espaços físico e social: basicamente crimes de rua cometidos em bairros de classes desfavorecidas e segregadas das metrópoles norte-americanas. (WACQUANT, 2008: 10)

Se retornarmos à história dos Estados Unidos, veremos que no século XIX, com a expansão do Novo Mundo, a população prisional era composta de imigrantes e pobres, o que não difere 
da função atual das prisões, segundo Wacquant (2008), de administração e de regulação da pobreza, do gueto e do trabalho desqualificado. $\mathrm{O}$ crescimento da população carcerária teve como consequência mais gastos que os alocados para políticas sociais e, em 1998, as penitenciárias eram a terceira maior fonte de empregos no país, proporcionalmente ao aumento das privatizações do setor. Além disso, o cárcere em massa contribui para o crescimento da economia informal, favorecendo empregos temporários e abaixo da linha da pobreza, que são o motor do capitalismo exploratório.

Logo, para que serve a prisão no século XXI? A partir desta indagação Wacquant (2003) traça uma reflexão política do sentido da pena se afastando de uma análise dos objetivos da pena em si. Assim, busca as relações entre o que nomeia de Estado Penal e as características oriundas da liberalização econômica, mostrando os caminhos como o modelo punitivo de encarceramento em massa que surge nos Estados Unidos e como a insegurança gerada pela menor intervenção estatal se propaga para países da Europa e América Latina. Dessa forma, examina detalhadamente o caso americano mostrando como o recuo da ação do Estado nas políticas de proteção social converteu a luta contra a pobreza em uma luta contra os pobres, onde a responsabilidade individual surge como principal movimento.

Em resposta ao desmantelamento da rede de assistências antes prestadas pelo Estado, surgem como substitutas formas disciplinares com a transformação, como assinala Wacquant (2003), dos mecanismos de serviço social em instrumentos de vigilância e controle, com a fixação da população que utiliza tais serviços nos guetos. Entretanto, a face mais dura desse processo é o encarceramento que, segundo o autor, não é direcionada para os criminosos perigosos, e sim para a juventude dos guetos, principalmente envolvida com o tráfico varejista que drogas. Wacquant (2003) classifica o gueto como local do controle da força de trabalho e manutenção das distâncias sociais. Entretanto, o que observa é que a prisão parece estar tomando o seu lugar. 
A nova demanda por ordem vai exigir o controle do tempo livre. A prisão não é mais lucrativa pelo trabalho dos presos, mas pela sua gestão, a ser terceirizada e privatizada, pela sua simbiose com as periferias urbanas e pelo seu capital simbólico. A indústria do controle do crime vai gerar uma nova economia, com seus medos, suas blindagens, suas câmeras, suas vigilâncias, sua arquitetura. A segurança privada vai substituir a construção civil como grande absorvedora de mão de obra desqualificada. (BATISTA, 2012: 8).

Segundo dados de julho de 2013 (CIA, 2013) os países com maior população, em ordem decrescente, são: China, Índia, Estados Unidos da América, Indonésia e Brasil. Em contrapartida, quando se trata de população carcerária, os números não correspondem a essa ordem; o país com maior população carcerária do mundo é os Estados Unidos da América (2,2 milhões), seguido por China (1,6 milhões), Rússia (700 mil) e Brasil (514 mil). No Brasil, em um período de 20 anos, a população carcerária cresceu cerca de $350 \%$ (DIREITO DIRETO, 2012)

Wacquant (2001) também se preocupa com a globalização das políticas de "tolerância zero" e como estas transferem o problema da criminalidade para o âmbito moral, retirando a responsabilidade das desigualdades geradas pelo capitalismo. Assim, a lógica neoliberal utiliza da necessidade da intervenção do Estado somente para que os indivíduos tomem decisões no mercado. Porém, estas escolhas, para os pobres, são restritas ao trabalho precário. Assim, as políticas de tolerância zero não correspondem a um aumento real da criminalidade, e sim a uma necessidade de controle das classes pobres. É reproduzida também uma cultura de medo, que torna privados os bens públicos e contribui para o individualismo e a segmentação, sobretudo entre as classes (DORNELES, 2003). $\mathrm{Na}$ visão dominante atual, segundo Silva (2004), a conduta criminosa é explicada pela anomia da justiça e as análises tendem a cair sobre o aparelho repressivo. Um problema fundamental de tal análise é o de que, a partir do momento em que o crime passa a ser fruto da ineficácia dos modelos de controle estatais, sua solução é 
encontrada exatamente na manutenção de tais mecanismos. Eis o crescimento do eficientismo penal (DORNELES, 2003), em que a política criminal é apresentada como única forma de estabelecer a ordem.

Assim, seguindo uma tendência da criminologia crítica, podemos dizer que o crime não está na lei e nem no fenômeno real em si, está na relação social e na crença compartilhada sobre ele. $\mathrm{Ou}$ seja, surge a partir de um discurso construído e de olhares distintos sobre os comportamentos. Dessa forma, as penas destinadas a determinados crimes e a determinados indivíduos são exercícios de poder, pois são seletivas e fruto de decisões políticas.

\section{3 - Impactos neoliberais na segurança pública brasileira}

Embora no Brasil não seja observada uma condução meramente punitiva em seu Código Penal, para Souza (2012) diversas são as fontes que nos dizem que o passado autoritário da ditadura militar não se rompeu, sobretudo no interior das instituições policiais. Um exemplo do poder punitivo do Estado nos é dado pelo relatório anual dos direitos humanos elaborado pela Anistia Internacional referente ao ano de 2011. O número de execuções legais em vinte países com pena de morte (exceto a China, que não divulga os dados) foi de 676. No Brasil, onde a pena capital não existe legalmente, o número de mortes em ações policiais, grande parte fruto dos "autos de resistência" nos estados do Rio de Janeiro e São Paulo foi de 961, 41,16\% a mais do que em todo o planeta (Figura 1). 


\section{Figura 1 - Mortos em execuções por pena capital - Mundo e Brasil, 2011}

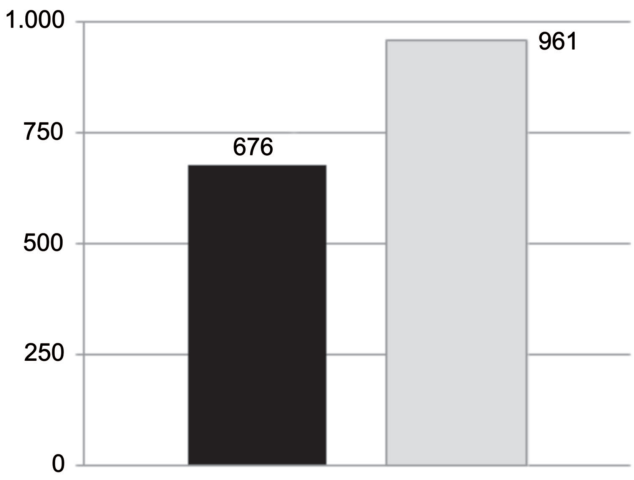

- Mortos de execução por pena capital em todos os países onde é legalizada (exceto China)

$\square$ Mortos em ações policiais no Brasil nos estados do Rio de Janeiro e São Paulo

Fonte: ANISTIAINTERNACIONAL (2012).

O país não rompeu com a tradição oligárquica pré-ditadura, que compactua com o elitismo em que a burguesia exige um Estado que "pague contas" a ela. Neder (1996) afirma ainda que a nossa formação social colonial nos levou a um controle social absoluto oriundo da cultura Ibérica. Hollanda(1973) discuteo distanciamento entre o Estado e a sociedade excluída e marginalizada, e que tal característica tem conexão com o conservadorismo predominante dos povos ibéricos que colonizaram a América. A partir das questões referentes à escravidão e ao patriarcalismo se é capaz, segundo o autor, de entender o motivo das formas sociopolíticas da mentalidade patriarcal no Brasil moderno. Também Faoro (1995) parte da hipótese de que no Brasil há uma histórica concentração de poder, como herança do período colonial corrupto e burocrata, características estas amplamente espelhadas nas relações sociais no país. Ainda segundo este autor, o poder sempre se concentrou na mão de uma elite dominante, a quem define como "estamento burocrático", que possui caráter patriarcal. Se essas características outrora eram identificadas nas figuras dos coronéis e senhores de engenho, 
com a vitória das idéias democráticas - vitória mais aparente que real - ele continuou a imperar sob outro molde, constituído de militares, bacharéis, médicos, enfim, altos funcionários públicos ou agentes do Estado em todos os seus poderes (FAORO, 1995: 263).

Além disso, de acordo com Dornelles (2003), desde o primeiro momento de colonização, o Brasil é submetido a uma cultura de extermínio. Essas chagas do passado não foram vencidas pela tardia democratização do país e, pelo contrário, segundo Pastana (2009), na nova República, constituída nos anos 1980, se viram emergir políticas sociais voltadas para o assistencialismo e as relações com o Estado de forma arbitrária e ilegal, o que também é observado na Justiça Penal, que trata com descaso a Constituição de 1988.

No caso do Brasil falta uma certa coragem em assumir o discurso de deslegitimação do Estado Penal, porque o desejo de punir instaurado se ancora em permanências históricas nas quais se imbricam a colonização genocida, a escravidão e a cultura inquisitorial ibérica. (BATISTA, 2012: 6)

Porém, o que o neoliberalismo traz de novo? Wermuth (2010) afirma que as raízes históricas e o passado escravagista brasileiro, por si só, tornaram o sistema punitivo do país um meio de controle social que visa uma administração das classes perigosas. Entretanto, a implementação das reformas neoliberais no Brasil incrementou à histórica seletividade o fator econômico. Isso porque um grande contingente se tornou disfuncional para o sistema produtivo por conta de sua falta de capacitação ou pela mão de obra se tornar desnecessária. As reformas neoliberais são marcadas por privatizações, cortes de gastos nas áreas sociais e privilégios aos setores financeiros. Assim, os ganhos na produtividade surgem a partir da degradação do trabalho, gerando como consequências marginalidades econômicas e sociais. Estes marginalizados "são consumidores falhos para os quais só resta a segregação, tanto 
pela via da marginalização social e espacial, quanto por meio do encarceramento em massa e da eliminação pura e simples a partir da intervenção violenta do sistema punitivo" (WERMUTH, 2010: 13). Antes do extermínio, porém, cria-se um discurso que o legitime: o neoliberal, que torna o Estado penal um potente motor cultural e promove um deslocamento do social para o penal (Batista, 2012).

Segundo Batista (2013), ações violentas em favelas demonstram a expansão do "Estado Policial", antagônico ao Estado de Direito, que credita às ações repressivas o sucesso das políticas de segurança pública. Dessa forma, a polícia brasileira atua com o objetivo de conquistar territórios inimigos apoiados pela mídia e pela opinião pública. Chacinas em favelas, invasão de domicílios, abordagens ostensivas e proibição de ações cotidianas são toleradas em nome de uma suposta ordem e é o que ocorre, por exemplo, no caso da implantação das Unidades de Polícia Pacificadora (UPP's) no Rio de Janeiro que, na verdade, promovem uma militarização da vida dos pobres. Ações semelhantes, se realizadas em bairros nobres, por exemplo, seriam consideradas como estado de sítio. Batista (2003) afirma que a política criminal é a única política pública que o neoliberalismo agencia para a manutenção do jogo mercadológico. Isso porque a precarização do trabalho faz com que a criminalização surja como o ato do governo para administrar os conflitos que ele criou e a população que ele marginalizou.

Tal sentimento de insegurança e transformação da questão da violência em uma indústria se transfigura em um significante aumento da procura pela segurança privada, o que reflete também a descrença da população em relação à eficiência dos serviços estatais. Com o objetivo de investigar o perfil das empresas de segurança privada que possuem autorização de funcionamento concedida pelo Ministério da Justiça/Polícia Federal foi realizado o Primeiro Estudo do Sindicato das Empresas de Segurança Privada, Segurança Eletrônica e Cursos de Formação do Estado de São Paulo (SESVESP). Segundo o estudo, em maio de 2011 o Brasil possuía 1.498 empresas de segurança privada autorizadas, que empregavam cerca de 540 mil vigilantes. Desse total de empresas, 
429 atuavam no estado de São Paulo (cerca de 29\%). Já em escala nacional, a análise comparativa em um menor espaço de tempo também aponta um aumento vertiginoso no número de empresas do segmento: no período de janeiro de 2010 a dezembro de 2012, houve a autorização de 1.008 novas empresas de segurança privada no Brasil, contra 513 canceladas, com o saldo de 495 novas empresas (Figura 2).

Nesse sentido, segundo Batista (2012), a obsessão por segurança, como mostrada nos dados anteriores, e a demanda por punição e castigo, representam uma simbiose entre o mercado para a segurança e a segurança para o mercado, preconizadas pelo discurso neoliberal.

Figura 2 - Saldo de empresas de segurança privada no período de janeiro de 2010 a dezembro de 2012

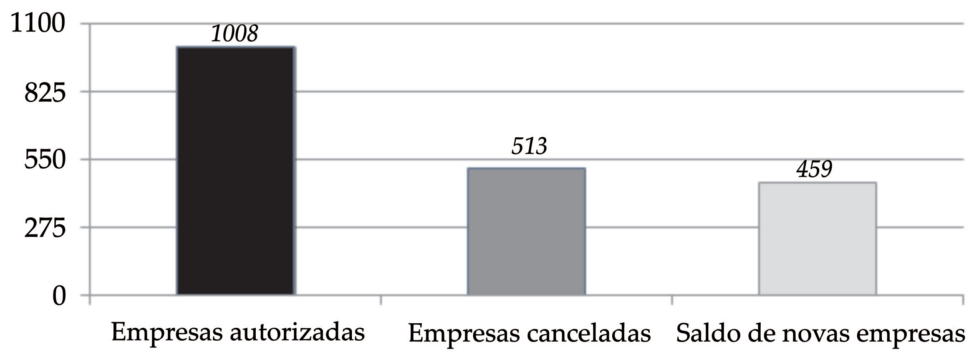

Fonte: SESVESP (2012).

Apesar das diferentes posições governamentais que ocuparam o poder desde a redemocratização brasileira, os principais investimentos em segurança pública ainda se concentram na repressão, para construção de penitenciárias e na capacitação de recursos penais. Dados comparados dos anos de 2008 e 2009 coletados do Departamento de Execução Penal (DEPEN), vinculado ao Ministério da Justiça, confirmam o avanço no número da população carcerária e de penitenciárias em todo o 
Brasil. No período de um ano (2008 para 2009), no Brasil, houve um total de 28.407 novos presos nos estabelecimentos penais. Estes também tiveram um aumento vertiginoso, como aponta a Figura 3.

\section{Figura 3 - Gráfico de Estabelecimentos Penais}

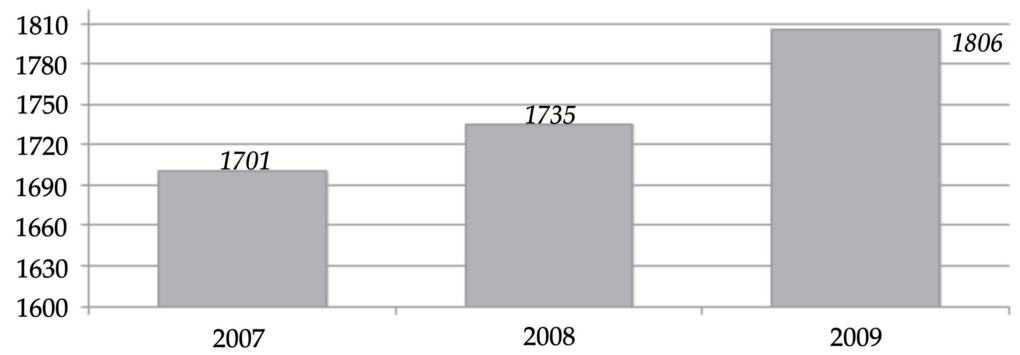

Fonte: BRASIL, Ministério da Justiça (2011).

A pesquisa "Brasil atrás das grades", de dezembro de 2012, traça as características do nosso sistema penal: o Brasil foi o país que mais criou vagas no sistema carcerário nos últimos 20 anos, passando de 60 mil vagas para 306 mil. Ainda assim, há um déficit de 208.085 vagas no sistema prisional. Desses presos, $30 \%$ não foram devidamente condenados, o que corresponde a 173 mil presos provisórios. A maioria dos presos são condenados a penas de 4 a 8 anos e os crimes responsáveis por grande parte dos aprisionamentos (94\%) são apenas nove, o que indica uma espécie de "processo seletivo" sobre o que deve ser, de fato, criminalizado. São eles: tráfico de entorpecentes, furto, quadrilha, receptação, porte de armas, estupro, homicídio, roubo e latrocínio. Além disso, $93,5 \%$ dos presos são homens, com mais de $50 \%$ com somente o ensino fundamental completo e cerca de $75 \%$ entre a faixa etária de 18 a 34 anos.

Segundo dados do Mapa do Encarceramento (BRASIL, 2014), no que diz respeito ao fator raça/cor, é possível observar 
também uma seletividade racial no sistema prisional brasileiro. Em todo o período analisado pelo estudo, de 2005 a 2012, existiam mais negros presos no Brasil, sendo que o aumento de presos negros cresce à medida que aumenta a população prisional. Em 2012 havia 292.242 negros presos e 175.536 brancos, ou seja, $60,8 \%$ da população prisional era negra. Em 2012, para cada grupo de 100 mil habitantes brancos acima de 18 anos havia 191 brancos encarcerados, enquanto para cada grupo de $100 \mathrm{mil}$ habitantes negros acima de 18 anos havia 292 negros encarcerados. Proporcionalmente, o encarceramento de negros foi 1,5 vez maior ao de brancos. É importante ressaltar que cresce a denominação de "outros" na categoria raça/cor pelos gestores penitenciários responsáveis pelo preenchimento de relatórios utilizados na pesquisa, o que dificulta, apesar de não inviabilizar, a análise dos dados.

O próprio nascimento da norma penal, segundo Martini (2007), já aponta para a defesa dos interesses de grupos dominantes. Exemplo é o tratamento distinto entre crimes públicos e crimes privados, em que o roubo tem punições e penas mais severas do que o crime de sonegação fiscal, que é muito mais abrangente em termos de consequências à população. Tal fato demonstra não só valores neoliberais e individualistas, como também o interesse público voltado para determinadas classes, classes essas que "financiam as campanhas eleitorais dos parlamentares, que fazem lobbys para a aprovação de leis que os beneficiam e que legitimam seus interesses minoritários através dos meios de comunicação" (MARTINI, 2007: 2).

Atualmente, segundo Pastana (2009), a maioria dos projetos de lei voltados à criminalidade pelo legislativo brasileiro em um período de 2003 a 2007 (cerca de 97\%) foram no sentido de agravar penas e tornar a legislação mais autoritária. Os crimes de colarinho branco praticamente não são discutidos. Sendo assim, a Justiça Brasileira, sob um discurso de defesa da democracia, atua em contradição com os princípios de sua consolidação, pois "nosso discurso penal hegemônico congrega elementos absolutamente contraditórios, como repressão severa e penas alternativas, 
leis duras e garantias processuais, encarceramento em massa e proteção aos direitos humanos" (PASTANA, 2009: 127). Embora haja reconhecimento das novas alternativas de cumprimento de penas, ainda são pouco expressivos seus usos no Brasil.

\section{Considerações Finais}

A partir da análise histórico social do Brasil é possível observar a reprodução de um Estado punitivo que visa o encarceramento e o controle, fundamentalmente das classes excluídas dos meios de produção, colaborando para a criação de um estereótipo de inimigo comum para a sociedade (também a mais vitimada pela violência urbana): pobre, negro, jovem e do sexo masculino. Tal imaginário compartilhado faz reproduzir na população uma sensação de insegurança no contexto urbano, o que colabora para a manutenção, legitimação e reprodução não só do preconceito, da segregação e da própria violência, mas também na busca de meios de segurança privada e cobrança de aumento punitivo dos mecanismos estatais.

O neoliberalismo não foi capaz de suprir a demanda social nem de satisfazer as necessidades do nosso país e vem sofrendo crises nos países onde vigora. Isso porque suas contradições fizeram crescer a necessidade de um governo que visasse, por exemplo, programas de inclusão social, e não só econômicos, por parte do Estado. Dessa forma, na segurança pública, estão em embate os discursos que defendem a manutenção da ordem em contraponto ao paradigma da transformação social. Estamos então em um embate onde entram em jogo os interesses entre minorias e maiorias, onde os vencedores, se é que eles existem, dependerão, fundamentalmente, da forma de governo desta e das próximas gerações. 


\section{Referências}

ANDRIOLO, L. J. A Reforma do Estado de 1995 e o Contexto Brasileiro. XXX ENCONTRODA ASSOCIAÇÃONACIONAL DE PÓS-GRAGUAÇÃOE PESQUISA EMADMINISTRAÇÃO (ANPAD), 2006, Salvador. Anais... Salvador, 2006.

ANISTIA INTERNACIONAL. Relatório anual dos direitos humanos de 2011. [S.1.], 2012. Disponível em: <https://goo. gl/66DUSi>. Acesso em: 25 julho 2013.

BATISTA, N. Mídia e sistema penal no capitalismo tardio. Revista Brasileira de Ciências Criminais, "Revista Especial", 8o Seminário Internacional, n. 42, 2003.

BATISTA, V. M. Adesão subjetiva à barbárie. In. BATISTA, V. M. Loïc Wacquant e a questão penal no capitalismo neoliberal. Rio de Janeiro: Revan, 2012.

BATISTA, V. M. Uma guerra particular. Carta Capital, São Paulo, 8 de julho de 2013. Disponível em <http://goo.gl/9UDNBn>. Acesso em: 8 jul. 2013.

BOBBIO, N. Liberalismo e Democracia. São Paulo: Ed. Brasiliense, 1994.

BRASIL. Ministério da Justiça. Sistema Penitenciário no Brasil - Dados Consolidados. Brasília, DF, 2011. Disponível em <http://goo.gl/68UU8x>. Acesso em: 24 abr. 2011.

BRASIL. Secretaria Geral da Presidência da República. Mapa do Encarceramento: os jovens do Brasil. Brasília, DF, 2014. Disponível em <http://goo.gl/5Odzo7>. Acesso em: 23 abr. 2015.

CENTRAL INTELLIGENCE AGENCY (CIA). The World Factbook. USA, 2013. Disponível em: < https://goo.gl/jdReX4>. Acesso em: 26 jul. 2013.

COSTA, E. V. Da Monarquia à República. 7a. ed. São Paulo: Fundação Editora da UNESP, 1999. 
DIREITO DIRETO. O Brasil atrás das grades. São Paulo, 2012. Disponível em <http://goo.gl/vR7aYh>. Acesso em: 26 jun. 2013.

DORNELLES. J. R. W. Conflito e Segurança: entre pombos e falcões. Rio de Janeiro: Ed. Lumen Juris, 2003.

FAORO, R. Os donos do poder: formação do patronato político brasileiro. 10ª ed. São Paulo: Globo, 1995.

FENAVIST. Movimentação das Empresas do Segmento. São Paulo, 2013. Disponível em: <http://goo.gl/v8EtK6>. Acesso em: 20 fev. 2013.

FIORI, J. L. O Brasil e seu "entorno estratégico" na primeira década do século XXI. In. SADER, E. (Org.). 10 anos de governos pósneoliberais no Brasil: Lula e Dilma. São Paulo: Ed. Boitempo, 2013.

GARCIA, M. A. Dez anos de política externa. In. SADER, E. (Org.). 10 anos de governos pós-neoliberais no Brasil: Lula e Dilma. São Paulo: Ed. Boitempo, 2013.

HOLLANDA, S. B. Raízes do Brasil. $7^{\mathfrak{a}}$ ed. Rio de Janeiro: José Olympo, 1973.

JOVCHELOVITCH, S. Representações Sociais e Esfera Pública A construção simbólica dos espaços públicos no Brasil. Petrópolis: Ed. Vozes: 2000.

KARAM, M. L. A Esquerda Punitiva. Discursos Sediciosos: crime, direito e sociedade, n. 1, ano 1. Rio de Janeiro: Ed. RelumeDumará, 1996.

MACEDO, U. B. Liberalismo e Justiça Social. São Paulo: Ed. IBRASA, 1995.

MANCEBO, D. Modernidade e produção de subjetividades: breve percurso histórico. Revista Psicologia: Ciência e profissão. v. 22, n. 1, 2002. 
MARTINI, M. A seletividade punitiva como instrumento de controle das classes perigosas. MPMG Jurídico. Belo Horizonte, 2007.

MAURIEL, A. P. O. Combate à pobreza e (des) proteção Social: dilemas teóricos das novas políticas sociais. Estudos de Política e Teoria Social. n. 14 e 15, 2006.

MIRANDA, A. B.; MIRANDA, G. J.; VERÍSSIMO, M. P. Ajuste neoliberal e a crise do Estado: necessidade de se retomar a autonomia dos Estados nacionais. IV Simpósio Internacional: o Estado e as Políticas Educacionais no Tempo Presente. Anais... Uberlândia/MG, 2008.

NEDER, G. Absolutismo e punição. Discursos sediciosos: crime, direito e sociedade, n. 1, ano 1, 1996.

NEGRÃO, J. J. O. O Neoliberalismo na Redemocratização Brasileira. Lutas Sociais, n 1, 1996.

PASTANA, D. Justiça Penal Autoritária e Consolidação do Estado Punitivo na Brasil. Revista Sociologia Política, v. 17, n. 32, 2009.

SADER, E. A construção da hegemonia pós-neoliberal. In. SADER, E. (Org.). 10 anos de governos pós-neoliberais no Brasil: Lula e Dilma. São Paulo: Ed. Boitempo, 2013.

SANTOS, R. D. Criminologia crítica e violência: o sistema penal como ultima ratio. CEDES - Centro de Estudos Direito e SOCIEDADE - boletim/março de 2007. Disponível em: <http://goo.gl/IXagXz>. Acesso em 11 maio 2015.

SESVESP. Primeiro Estudo sobre o segmento prestador de serviços de segurança privada. São Paulo, 2012. Disponível em: $<$ http:// goo.gl/9DsxjX>. Acesso em: 13 fev. 2013.

SILVA, L. A. M. Sociabilidade Violenta: por uma interpretação da criminalidade contemporânea no Brasil urbano. Sociedade e Estado, v.19, n. 1, 2004.

SOARES, L. T. R. Ajuste neoliberal e desajuste social na América Latina. Rio de Janeiro: Ed.UFRJ, 1999. 
SOUSA, D. T. A Comissão da Verdade e a Democracia no Brasil. Revista Sociologia, n. 40, 2012.

SOUZA, H. R. C. et al. Todo crime é político (entrevista com Nilo Batista). Caros Amigos, ano 7, n. 77, 2003.

TAVARES, V. "Cada país tem o número de presos que decide politicamente ter" (entrevista com Raúl Eugenio Zaffaroni). Brasil de Fato, São Paulo, 29 de julho de 2013. Disponível em: < http://goo.g1/Iy9GMa>. Acesso em: 30 jul. 2013.

WACQUANT, L. As Prisões da Miséria. Rio de Janeiro: Jorge Zahar, 2001.

WACQUANT, L. O lugar da prisão na nova administração da pobreza. Revista Novos Estudos, n. 80, 2008.

WACQUANT, L. Punir os Pobres: a nova gestão da miséria nos Estados Unidos. Rio de Janeiro: Revan, 2003.

WERMUTH, M. A. Direito Penal versus Sociedade de consumo: como eliminar o "perigo" representado pelos "consumidores falhos". Cadernos da Escola de Direito e Relações Internacionais, v. 2, n. 13, 2010.

ZAFFARONI, E. R. Em busca das penas perdidas. Rio de Janeiro: Revan, 1991. 
$\mid 226$ |

Segurança pública e lógica neoliberal: a realidade brasileira 